\title{
Replies to critics
}

\author{
John Martin Fischer
}

Published online: 5 December 2010

(C) The Author(s) 2010. This article is published with open access at Springerlink.com

I wish to begin by thanking my three "critics," Ben Bradley, David Velleman, and Derk Pereboom, for their extremely thoughtful, generous, and insightful comments on my book. I won't be able to address all of their points, but I'll do my best to grapple with at least the main worries. My colleague and good friend, Paul Hoffman, died during the time of writing this piece; I would like to dedicate this reply to Paul.

\section{Reply to Bradley}

Bradley nicely captures the thrust of the Epicurean argument that death cannot be bad for the individual who dies as follows:

Dead people have no sensations, a fortiori no bad sensations. Nothing is bad for us unless it is, or causes, some bad sensation (the experience requirement). Thus being dead is not bad; nor is the event of one's death, since it does not cause one to be in a bad state. (Bradley 2010)

Following Thomas Nagel and others, I have sought to attack the experience requirement (in its different forms). The various examples I have invoked (sometimes borrowing from others, such as Nagel, Nozick, and McMahan) have been in the service of this assault on the experience requirement. So, the examples of the man betrayed behind his back, the woman secretly videotaped in her bedroom, and the person whose daughter dies on a Himalayan trek, are all cases in which an individual can be harmed by an event, even if he or she never has any unpleasant experience as a result of it—or so I would argue. Similarly, in my version of Nagel's betrayal case in which White is a "counterfactual intervener"

\footnotetext{
J. M. Fischer ( $₫)$

University of California, Riverside, CA, USA

e-mail: John.Fischer@ucr.edu
} 
poised to prevent the information from reaching the man, I say that the man is harmed, even though he cannot have any unpleasant experiences as a result of the betrayal. I thus sought to connect the contemporary literature on death with the literature on the Frankfurt-Style Counterexamples to the Principle of Alternative Possibilities:

Imagine first that the example is as described by Nagel. You are betrayed behind your back by people who you thought were good friends, and you never actually find out about this or have any bad experiences as a result of the betrayal. But now suppose that these friends were (very) worried that you might find out about the betrayal. In order to guard against this possibility, they arrange for White to watch over you. His task is to prevent you ever from finding out about the betrayal. So, for example, if one of the individuals who betrayed you should decide to tell you about it, White can prevent him from succeeding: White can do whatever is required to prevent the information from getting to you. Or if you should begin to seek out one of the friends, White could prevent you from succeeding in making contact. I simply stipulate that White is in apposition to thwart any attempt by you or your friends to inform you of what happened. (Fischer (1997, p. 39), in Our Stories; for discussions of aspects of Frankfurt-Style Cases, see Fischer (2006)

Bradley points out that all of these examples are different in an important way from his example of Derk's stealing the tickets, which harms Ben in part because it deprives Ben of some good experiences he would otherwise have had. Bradley attributes to me a view that (according to him) didn't even have a name until Ben dubbed it, "More Intrinsic Badness":

MIB: Death is bad for its victim in virtue of bringing about something that is intrinsically bad for her.

Bradley finds the view-or perhaps the fact that someone would be so foolish as to attempt to defend it- "exciting"! Of course, one hates to diminish any excitement generated by one's ideas; but, although I find MIB attractive, I hadn't really identified it as such, and I didn't intend to be defending it. Perhaps I should embrace it, along with a deprivation account. Bradley points out that the deprivation view of death's badness is compatible with supplementing it with MIB, but my intention in offering the various examples was simply to offer support for the deprivation account of death's badness.

To explain. The Epicurean argues that death cannot be bad for an individual for various reasons. One reason is that the subject of the harm fails to exist when the event that is putatively harmful takes place. A related worry is that it is thus mysterious when the alleged harm takes place; can it take place at a time when the subject does not exist? Can it take place at a time when the supposedly harmful event has not yet taken place? Finally, an Epicurean will insist that nothing can be bad for an individual — can harm the individual — that does not involve or cause unpleasant experiences.

In presenting the various examples, I was simply seeking to address the last Epicurean contention-the experience requirement. This was in service of a defense 
of the deprivation account: death is a bad thing for an individual insofar as it deprives him or her of what would on balance be valuable. (Of course, it is important to the reply to Lucretius offered by Brueckner and me-to be discussed below in my reply to Velleman - that death is not merely an experiential blank; it is also a deprivational blank.) Being a permanent experiential blank (on the working hypothesis of these debates), death cannot involve or cause any unpleasant experiences; thus, if one wishes to defend the claim that death really is bad for an individual, one must address the Epicurean worry that nothing can be bad for an individual without involving or causing unpleasant experiences for that individual.

\section{Reply to Velleman}

\subsection{Prisoners and Trolleys}

David believes that there is an important difference between schematized stories (or hypothetical cases) such as the Prisoners' Dilemma, on the one hand, and the Trolley Problem, on the other. He says:

...The story of the prisoners serves as a prop in a demonstration of how to use the matrix as a representation of the incentives present in situations that arise in real life; and the story thereby aids us in abstracting those incentives from the messy details of life-abstracting them, ultimately, with the matrix rather than the story itself.

The Trolley Problem has no such use. No one would point to a real situation and say, 'That's a Trolley Problem', in the way that we often say, that's a Prisoners' Dilemma'. We don't often have to choose between doing a few harms and allowing many, but when we do, the structure of our choice is obvious: there are the harms we could do, and then there are the harms we would otherwise allow. We don't need a matrix in order to see what's going on, and so the Trolley Problem doesn't reveal an underlying structure of our situation.

The point of the Trolley Problem is to pit two moral intuitions against one another: on the one hand, our intuition that killing innocents is strictly forbidden; on the other, our intuition that the number of deaths should be minimized. ... By contrast, the Prisoners' Dilemma is not supposed to reveal whether we think that cooperation is better than rugged individualism. ... There is no test of moral intuitions, as there is in the Trolley Problem. (Velleman 2010)

We-sometimes, at least—do indeed face "Trolley Problems" in real life, either at the policy level or in our personal lives. Surely we confront difficult questions of triage in emergency situations, and, at the policy level, questions about the distribution of scarce resources. Presumably, how best to structure healthcare delivery is just such an issue. At least some of the cases in the suite of examples that comprise the Trolley Problem are relevant to such issues, and the analysis of the cases may bear on the policy issues. 
But I am willing to stipulate Velleman's points about the important differences between the Prisoners' Dilemma and the Trolley Problem for the sake of discussion. In particular, I am willing to grant that the point of invoking the Prisoners' Dilemmas is not so much to elicit and highlight conflicting moral intuitions, but to identify an abstract payoff structure and to help us to see that it is instantiated in various real-world contexts.

Not surprisingly, however, I still find something of value in Trolley-ology. I would suggest that the value of the Trolley Problem lies primarily in the solutions that naturally suggest themselves. More carefully, I think it is valuable-at least as a pedagogical or heuristic device-to see how such principles as the Doctrine of Double Effect, the Doctrine of Doing and Allowing, and the Doctrine of Harming and Failing to Benefit naturally suggest themselves as solutions to the Trolley Problem and are also central to the moral analysis of various pressing real-world problems. (For some discussion, see Fischer and Ravizza (1992).) Perhaps, then, thinking about the Trolley Problem (at least in certain pedagogical contexts) is not useful in the same way as thinking about the Prisoners' Dilemma. Whereas attending to the Prisoners' Dilemma can help us to see that many contexts in real life have the same abstract structure or payoff matrix as the Prisoners' Dilemma, thinking about the Trolley Problem can identify and throw light on various principles that purport to be solutions. And these principles are significant in addressing many real-life problems. Obviously, the Doctrine of Double Effect is at least relevant to the moral evaluation of war and terrorism (among other issues, including abortion), the Doctrine of Doing and Allowing is relevant to the moral evaluation of euthanasia, and the Doctrine of Harming and Failing to Benefit is relevant to the moral evaluation of the challenges of helping others in need throughout the nation and world.

I would suggest that both the Prisoners' Dilemma and the Trolley Problem point us to real-world problems, but that they do so in different ways. The Prisoners' Dilemma points us in the first instance to the ubiquity of situations in which individual rationality leads to a certain sort of group irrationality (as it were). We can thus seek to "change the rules" in such contexts to seek to bring individual rationality in harmony with what's best for everyone. As Velleman puts it, the Prisoners' Dilemma is not meant to test whether we think that cooperation is better than rugged individualism; rather, it helps us to identify the various contexts in which rugged individualism leads us astray, even by its own lights. In contrast, the Trolley Problem points us in the first instance to certain salient and appealing moral principles-principles that tap into deep parts of our moral orientation (including, but not limited to, moral intuitions). Of course, we may also wish to subject those principles to additional scrutiny in various ways, including by constructing additional schematized cases. We can then seek to apply these principles to realworld problems.

Perhaps I can summarize my point as follows. Prisoners' Dilemmas send us to real-world contexts rather more "directly" than does the Trolley Problem. The point of the Prisoners' Dilemma is to take the relevant moral principles as fixed and to highlight useful applications of them, whereas the point of the Trolley Problem is to focus on difficulties with our moral principles with an eye to seeking to resolve 
these difficulties. In both cases we aim ultimately to resolve real-world problems. Moral analysis has many aspects, and it should not be surprising that stories have very different roles to play-even highly schematized and streamlined stories.

\subsection{Death}

Velleman says that re-reading the paper I wrote with Anthony Brueckner, "Why Is Death Bad?", has helped to codify a feeling he has had for some time that there is "something wrong" with our argument. I can tell you that an author hopes that some good will come of collecting his papers and publishing them together; whereas David's revelation might not be quite the sort of thing I had in mind, I appreciate David's fascinating ruminations on our paper.

Brueckner and I set out to explain the commonsense asymmetry in attitudes toward prenatal and posthumous nonexistence. Lucretius pointed out that posthumous nonexistence is the mirror-image of prenatal nonexistence, and thus, since we are indifferent to prenatal nonexistence, we should also be indifferent to the prospect of being dead in the future. Brueckner and I invoked a Parfitian asymmetry in attitudes toward past and future good experiences to address the argument of Lucretius. We said:

Imagine that you are in some hospital to test a drug. The drug induces intense pleasure for an hour followed by amnesia. You awaken and ask the nurse about your situation. She says that either you tried the drug yesterday (and had an hour of pleasure) or you will try the drug tomorrow (and will have an hour of pleasure). While she checks on your status, it is clear that you prefer to have the pleasure tomorrow. There is a temporal asymmetry in our attitudes to 'experienced good' that is parallel to [although, of course, the reverse of] the asymmetry in our attitudes to experienced bads: we are indifferent to past pleasures and look forward to future pleasures. (Brueckner and Fischer (1986, pp. 32-33), in Our Stories)

We went on to apply this point to the Mirror-Image Argument of Lucretius:

Death is a bad insofar as it is a deprivation of the good things in life (some of which, let us suppose, are 'experienced as good' by the individual). If death occurs in the future, then it is deprivation of something to which we look forward and about which we care-future experienced goods. But prenatal nonexistence is a deprivation of past experienced goods, goods to which we are indifferent. Death deprives of something we care about, whereas prenatal nonexistence deprives us of something to which we are indifferent. (Brueckner and Fischer (1986, p. 33), of Our Stories)

About this argument, Velleman says:

Brueckner and Fischer assume that even if the Epicureans abandoned this argument [based on the lack of existence of a subject] and conceded that death was a harmful deprivation, they could fall back on their argument from the temporal asymmetry in our attitudes. Brueckner and Fischer therefore set out 
to answer the asymmetry argument on the basis of premises that include the deprivation account. But I would argue that the asymmetry argument isn't meant to be independent of the other Epicurean arguments against the harm of death. Our indifference about pre-natal nonexistence is not adduced as independent grounds for being indifferent about posthumous nonexistence. Rather, the former indifference is adduced to remind us of the underlying reasons for it, which apply equally to the latter. The reasons are precisely that nonexistence has neither a subject nor a victim. Given that those reasons register with us when we consider the past, Lucretius suggests, they ought likewise to register with us when we consider the future. (Velleman 2010)

Velleman goes on to explore a suggestion for a reply to Lucretius that, in the end, he rejects because he takes it that it presupposes the (apparently) implausible (to him) supposition of the real passage of time.

Velleman's interpretation of the Mirror Image Argument is novel. Whereas most interpretations of Lucretius assume that he is providing an independent argument for the view that we should not consider our prospective deaths as regrettableindependent (say) of the "no-subject" argument of Epicurus-Velleman suggests that we understand it as a way of bolstering Epicurus's no-subject argument. It does this, according to Velleman, by highlighting a context in which we are indifferent to nonexistence putatively because it is subjectless. Crucially, Velleman says: “... the former indifference [to prenatal nonexistence] is adduced to remind us of the underlying reasons for it, which apply equally to the latter. The reasons are precisely that nonexistence has neither a subject nor a victim." He goes on to suggest that Lucretius is recommending that we apply these considerations to our attitudes toward death.

To clarify the argument Brueckner and I presented, consider the "blanks" before we were born and after we die. These blanks might be thought to be relevantly similar; arguably, Lucreitus is stating that they are indeed relevantly similar insofar as they are both experiential blanks without a subject. But our point is that these are not mere blanks; rather, they are blanks that are such that, if the blank hadn't occurred, the individual would have had some positive experiences. That is, they are not mere blanks, but deprivational blanks (as I stated in my reply to Bradley above), and the appropriate attitudes toward these blanks should reflect this fact. Since the blanks matter because they deprive us of certain experiential goods, and since there is a Parfitian asymmetry in our attitudes toward such goods (that is, we care about future experiential goods in a way in which we do not care about past experiential goods), it is appropriate to have asymmetric attitudes toward prenatal and posthumous nonexistence.

A problem with Velleman's interpretation of Lucretius's Mirror Image Argument is that one might as well conclude, from the symmetry of subjectlessness, that one should reevaluate one's attitudes toward prenatal nonexistence. That is to say, from the mere fact that prenatal and posthumous nonexistence equally involve the lack of a subject, it would not follow that we should be indifferent to posthumous nonexistence; we could equally conclude that we ought to regret our prenatal nonexistence. 
Bruekner and I are inclined to say that all parties to the dispute knew all along that both prenatal and posthumous nonexistence are subjectless; but the controversy has been about what follows from this indisputable fact. On our view, there is a crucial difference between the two subjectless periods; posthumous nonexistence deprives us of something we care about, whereas prenatal nonexistence deprives us of something to which we are indifferent. We have thus called into question Velleman's suggestion that it is "precisely" the subjectless nature of prenatal nonexistence that explains our indifference to it; rather, on our Parfitian approach, it is the fact that prenatal nonexistence deprives us of past goods that explains our indifference to it (on the assumption that it is rational to be indifferent to past goods, while caring about future goods).

\subsection{Immortality}

Velleman claims that, perhaps under Bernard Williams' influence, "projects" have come to be overrated in moral philosophy. I have some sympathy with this worry. Williams argued that inevitably we would lose our "categorical desires"-our projects - in an immortal life: Williams (1973a), reprinted in Fischer, ed. (1993). I have argued that, even so, the prospect of certain "repeatable" pleasures could propel us into immortal life: Fischer (1994a, b); reprinted in Fischer (2009). I'd like to revisit this issue briefly here.

We might distinguish two kinds of projects-other-focused and self-focused projects. Although Williams contends that all other-focused projects would necessarily disappear in an immortal life, I am not convinced. After all, there appear to be many such projects to keep one occupied a very, very long timemaybe forever, where "forever" is infinitely long life. At least, this is an open question; I don't think that Williams has said anything very persuasive to rule out the possibility of finding new other-focused projects as one goes on in an immortal life.

So, for example, there's the project of curing diabetes. Or cancer-all the various forms of it. This will keep one occupied a long time (unfortunately). But this is just the beginning of the list of diseases, and presumably new ones will pop up given enough time-frankly (and lamentably), even just a little. And there's alleviating poverty, hunger, achieving world peace, saving the oceans (and afortiori the whales and the blue-fin tuna), and so forth. You can perhaps see where this is headed; I do not see why even immortal creatures very much like us would lose the capacity to have other-focused projects. As older problems are solved, new ones will emerge. Even if all these problems are solved and the baseline for human beings (that is, the overall baseline for expectations for human flourishing in all relevant dimensions) is raised, we could presumably try to raise it further. Why not? And this will involve new other-focused projects, and so forth. Further, I don't see why a given individual couldn't make the transition from one project to the next project in an organic, coherent way - thus (arguably, at least) preserving personal identity.

But even if we grant Williams his claim-often accepted without much critical reflection by philosophers-that we would inevitably and necessarily lose the capacity for other-focused projects in an immortal life, we could still have 
self-focused projects, like meditation, prayer, enjoying fine music, art, food, and sex. (The term "self-focussed" might be a bit infelicitous; all I wish to emphasize is that a main point of the activities in question is a positive psychological state of the agent.) I agree with Velleman that philosophers have a lamentable tendency to conceptualize meaningfulness in terms of "projects", interpreted as in "gradeschool projects." It is almost as if life wouldn't be worth living if there weren't an article to be written or an anthology to be edited! Or, more broadly, life wouldn't be worth living if we weren't busy trying to accomplish something where, ideally, the accomplishment benefits others (or even human beings in general). But conceptualized more expansively and including self-focused projects (involving reliably repeatable positive experiences) as well as other-focused projects, an orientation toward projects needn't be so bad. I suspect that Velleman and I are in agreement in supposing that the enjoyment of certain basic experiences and pleasures might be enough to propel us into the future, even in the absence of anything much fancier. If you add spiritual and religious experiences into the mix, immortality doesn't seem all that bad. As Jonathon Glover once put it, at least one might want to try it for a few million years and see how it goes... (I offer some additional reflections on immortality in Fischer forthcoming.)

\subsection{The Plurality of Perspectives of Evaluation and Life-Stories}

Velleman expresses a worry about a certain sort of subjectivism in my views about narrativity and meaning. More specifically, I state that evaluation is purposedependent, and further that there is no hegemonic purpose with respect to which to evaluate an object or individual. So, for example, we can evaluate a sculpture in terms of aesthetic criteria and also moral criteria; who is to say whether the aesthetic or moral perspective should be the master perspective with respect to the evaluation of the sculpture? Similarly, we can evaluate a human being's life from various different perspectives, including aesthetic, prudential, and moral; again, who is to say which perspective should be considered hegemonic? It seems to me most natural to suppose that there are just different perspectives we take in evaluation, depending on our purposes, and that there is no "basic" or "fundamental" purpose. (Similarly, I contend that there is no hegemonic perspective from which our narratives get constructed or our stories get told.)

My main point here is that, unlike with a painting or sculpture, there is an anomalous discordance in the case of the evaluation of human lives. We act freely and thus are the authors of our narratives. The nature of our activities in leading our lives is therefore aesthetic: we are the authors of our stories. But the "typical" way of evaluating our lives would be moral and prudential, given facts about human purposes. So the nature of the activities and the standard modes of evaluation of them pull apart in a striking way.

If one wishes to defend an objective account of evaluation or narrativity, one would simply argue for the "designation" of (say) a perspective as fundamental for the task at hand-construction of the narrative or the evaluation of the life. What matters to me is that the context of the meaningfulness of our lives is a context in which there is a certain discordance: the evaluation of our lives in terms of moral 
and prudential reasons pulls apart from the aesthetic nature of the activities. The question of whether there is a hegemonic perspective with respect to the construction or evaluation of our narratives is orthogonal to this point, and I do not have a strong stake in denying that there exists such a perspective.

\section{Reply to Pereboom}

Pereboom contends that much (at least) of what gives human life its rich and compelling texture does not stem from free will, no matter how far back you trace or where exactly you seek to find the acts of free will. For Pereboom love is a central feature of our lives, and its etiology and even its maintenance is not typically due to free will-nor would it be desirable if free will played such roles. Also, we often think of ourselves as playing roles in larger schemes or "plans"-perhaps framed by God-in which our roles are, as it were, "given" to us but not formulated or embraced through acts of free will.

I do not have the space here to address Pereboom's point about our role in larger schemes or plans; perhaps I can simply state here that my view was intended to be more limited in scope. That is, my contention is that a specific kind of narrative value (relational value) - examples of which are learning from one's mistakes, flourishing as a result of one's efforts, and so forth-stems from exercises of free will. Pereboom usefully points out that my contention must be construed as restricted in scope, in order to be plausible, and I accept this insightful point.

In the limited space I have here, I want to focus on Pereboom's comments about love. To begin, note that Pereboom says:

Perhaps what is unacceptable is not being causally determined to love by the other party per se, but rather how one is causally determined, and that there are varieties of such determination that are not objectionable. (Pereboom, pp. 6-7)

I certainly agree with this statement, and I would also apply it to participation in a larger plan-as well as all other kinds of value. With respect to acting freely and moral responsibility, I am a Semicompatibilist_-I believe that certain sorts of causal determination are completely compatible with acting freely and moral responsibility: Fischer (1994), Fischer and Ravizza (1998), Fischer (2006). I would say the same thing about meaning and value in our lives.

On my view certain kinds of causal determination are compatible with acting freely; Pereboom, however, would disagree. So he would not think that certain agents (causally determined even in the "favored ways") are properly considered to be acting freely. Thus he might press his question about the role of free will. And upon reflection about love, I am inclined to agree that free will, however you interpret it, might not play a central role in love (and in our conceptualization of it). That is, I'm inclined to think that the libertarians, such as Robert Kane-as well as others who link love to free will-might be looking for love in all the wrong places.

Philosophically, as well as existentially, love is an incredibly complicated thing. There are many nuances I cannot explore here, but I am inclined to think that free will is not an important (or, at least, "positive" [more on this below]) component of 
the conceptualization of the value we find in the various sorts of love. I think love stands in contrast to moral responsibility more generally in this respect. Insofar as we are morally responsible agents, we are guided by Reason, or perhaps only slightly less metaphorically, we are guided by our distinctive capacity for reasonsresponsiveness. But love resists guidance by Reason. It is not just that the feelings are recalcitrant. By its very nature, love is mysterious, refractory, and spontaneous; phenomenologically, it feels passive rather than active, not just in its origination, but also its preservation.

To elaborate a bit, there are two distinct ways in which the locus of control might be "external" to an agent: either someone (or something) else is in control, or there is no locus of control. Moral responsibility is threatened if the locus of control is not internal to the agent in either of these ways-it does not matter, for the purposes of attributions of moral responsibility, whether the locus of control is external in one way or the other. In contrast, we care that our lover not be controlled by someone else, but we do not demand that she herself be in control. With respect to love (as opposed to moral responsibility), only the first way in which the locus of control can fail to be internal to the agent matters to us.

If one imagines being loved by someone entirely driven by wild, uncontrollable passion or perhaps a strong and steady but irresistible "basic" or even animalistic attraction for one - to all aspects of one-would this really be so bad? Would it add something we really care about or value to suppose that, in her quiet moments, one's lover reflectively endorses her passions? I doubt it. It wouldn't be objectionable if, even when one's lover seeks to detach herself from her powerful attraction and reflect on it, she unable to-and she remains powerless to resist the urgency of her love. Love is more like what's described by the great Johnny Cash song (written in part by June Carter Cash), "Ring of Fire":

Love is a burning thing

And it makes a fiery ring

Bound by wild desire

I fell into a ring of fire...

I fell into a burning ring of fire

I went down, down, down

and the flames went higher.

And it burns, burns, burns

the ring of fire

the ring of fire.

I think the feelings described by this song are familiar to anyone who has fallen in love. (Note the appropriateness of the word, "fallen.") It feels as if one is not in control.

But, despite all of this, I nevertheless think that free will plays some role in what we care about in love. That is, I'm still attracted to some kernel of truth in the quotation from Robert Kane in Pereboom's comments; although it is clearly very difficult to specify, I'm inclined to think that there is something to the intuitive idea that we care about or value our lover's embrace us freely. I recall that in the film, Bruce Almighty, the character played by Jim Carey wanted the character played by 
Jennifer Aniston to fall in love with him. In giving the Jim Carey character God-like powers, God (played by Morgan Freeman) said something like this: "Do anything you want, but don't mess with her Free Will." And there's something to this point.

In closing, allow me simply to sketch (in a preliminary way) my view about the role of free will in love. Morgan Freeman's-or should I say "God's" —advice captures something important; I don't want it to be the case that my lover is a mere puppet of mine (or, perhaps, of anyone else). If Jim Carey's character had bypassed Jennifer Aniston's character's free will, she would have become a mere puppet; Jim Carey's character would be behind everything, controlling it; this would then be a case of "self-love"-important, but certainly not all we want. So this suggests that part, at least, of what we care about is that our lover is not a mere puppet of anyone, including ourselves; I do not want the behavior of my lover to be produced (say) by hypnosis or direct stimulation of the brain by me. I do not want my lover's behavior to be directed by me; I want the behavior to be hers-I want her to be the source of behavior, even if I am in some sense its cause.

But this leaves it open that my lover is the "source" of her love for me without being guided or directed by Reason-without, that is, the guidance of Free Will. What probably plays the decisive roles in initial attraction and even subsequent maintenance are a suite of sub-rational mechanisms better studied by the psychologists (or perhaps experimental philosophers) than aprioristic philosophers. Even if these mechanisms are not under our control—are not reasons-responsivethey represent a deep and important part of us. Perhaps we care a lot about this part of us having a voice too-and love seems to be a place where it should be allowed to sing. As I pointed out above, our concern (with respect to control) in the case of love is primarily that the locus of control not be located in someone other than our lover-it is thus essentially a "negative" concern. In contrast with the context of moral responsibility, we do not insist that our lover be guided by Reason or any exercise of free will.

I recall the first day I met the woman who would become my wife: I remember her beautiful smile, those glinty white teeth, the lovely long hair, and ... I would of course be surprised and disappointed to discover that my wife was a mere puppet controlled by a team of neurosurgeons, nefarious or nice. So part of what I care about is, as it were, "negative"; I care that my lover is not a mere puppet of anyone else. But it would be nice if she loved me-despite her Better Self-for my smile, my hair [if I had any], those zingy and unpredictable "one-liners", or ...

Open Access This article is distributed under the terms of the Creative Commons Attribution Noncommercial License which permits any noncommercial use, distribution, and reproduction in any medium, provided the original author(s) and source are credited.

\section{References}

Bradley, B. (2010). Fischer on death and unexperienced evils. Philosophical Studies. doi:10.1007/ s11098-010-9667-0.

Brueckner, A., \& Fischer, J. M. (1986). Why is death bad? Philosophical Studies, 13, $213-221$. (Reprinted in Fischer, ed., pp. 221-230, 1993). 
Fischer, J. M. (Ed.). (1993). The metaphysics of death. Stanford, CA: Stanford University Press.

Fischer, J. M. (1994a). The metaphysics of free will. Oxford: Blackwell Publishers.

Fischer, J. M. (Ed.). (1994b). Why immortality is not so bad. International Journal of Philosophical Studies, 2, 257-270. (Reprinted by J. M. Fischer, ed., pp. 79-92, 2009).

Fischer, J. M. (1997). Death, badness, and the impossibility of experience. Journal of Ethics, 1, 341-353. (Reprinted by J. M. Fischer, ed., pp. 37-50, 2009).

Fischer, J. M. (Ed.). (2006). My way: Essays on moral responsibility. New York: Oxford University Press.

Fischer, J. M. (Ed.). (2009). Our stories: Essays on life, death, and free will. New York: Oxford University Press.

Fischer, J. M. (forthcoming). Immortality. In B. Bradley, F. Feldman, \& J. Johanssen (Eds.), Oxford handbook on death.

Fischer, J. M., \& Ravizza, M. (Eds.). (1992). Ethics: Problems and principles. Fort Worth: Harcourt Brace Jovanovich.

Fischer, J. M., \& Ravizza, M. (1998). Responsibility and control: A theory of moral responsibility. New York: Cambridge University Press.

Velleman, J. D. (2010). Comments on John Martin Fischer's Our Stories. Philosophical Studies. doi: 10.1007/s11098-010-9671-4.

Williams, B. (1973a). The Makropulos case: Reflections on the tedium of immortality. In B. Williams (Ed.), Problems of the self (pp. 82-100). Cambridge: Cambridge University Press. (Reprinted by J. M. Fischer, ed., pp. 73-93, 1993).

Williams, B. (Ed). (1973b). Problems of the self. Cambridge, UK: Cambridge University Press. 